recursos materiais e emocionais para suportar e superar a situação. A raiva e o ressentimento acompanham esses momentos, podendo direcionar-se à família e/ou profissionais. Num outro momento um pacto com Deus e promessas para obter a cura sem dor e evitando a morte. A passividade e/ou depressão sobrevêm, seguidas pela aceitação da realidade e da morte. É relevante a esperança nesse percurso.

Essas respostas referidas não abrangem a diversidade do processo de enfrentamento, que podem

\section{REFERÊNCIA BIBLIOGRÁFICA}

01. CARTANA, M.H.F.; HECK, R.M. Contribuição da antropologia na enfermagem: refletindo sobre a doença. Texto Contexto Enfermagem, Florianópolis, v. 6, n. 3, p. 233-240, 1997.

02. CRUZ, J.de la. El paciente, la familia y el equipo de salud frente a la enfermedad crónica.

Actual.Enferm., v. 1, n. 4, 1998.

03. LAZARUS, R.; FOLKMAN, S. Stress appraisal, and coping. Trad. Luiz Villas Boas. New York: Springer, 1984. apresentar intensidade e tempo variáveis, em outra seqüência ou simultânea. A falta de informações adequadas ou intercorrências podem dificultar a adaptação e aceitação da realidade.

A enfermagem deve reconhecer esses processos, diante da doença, para realização do cuidado. Dessa forma, ela utiliza métodos e estratégias de trabalho que auxiliem no direcionamento dos cuidados e incentivos à adoção de atitudes positivas diante de doenças e condições crônicas de saúde.

04. MINAYO, M.C.S. Abordagem antropológica para avaliação de políticas sociais. Rev. Saúde Pública. São Paulo, v. 25, n. 3, p. 233-238, 1991.

05. MURROW, E.J.; OGLESBY, F.M. Acute and chronic illness: similarities, differences and challenges. Orthopaedic Nursing, v. 15, n. 5, p. 47-51, 1996.

06. PHIPPS, W.L. et al. Enfermagem médicocirúrgica: conceitos e práticas clínicas. Lisboa: Lusodidacta, 1995. cap. 13, p. 225-246. Doença crônica.

\title{
O COMPUTADOR A BEIRA DO LEITO
}

\section{Yolanda Dora Martinez Évora*}

Trazer o computador para a beira do leito é, atualmente, uma das metas dos hospitais brasileiros e um grande desafio para a enfermagem. Considerando que a enfermagem brasileira atua de uma forma muito diversificada, com certeza será através da informatização que iremos sistematizar a prática de enfermagem e proporcionar uma assistência mais individualizada ao cliente.

A literatura e o cotidiano nos mostram que a enfermagem é o maior grupo no hospital de usuários de informações de cuidados a saúde e o enfermeiro pode ser considerado o centro do processo de assistência ao paciente. É ele quem coleta informações cruciais do paciente, comunica-se com médicos e departamentos de apoio, atualiza o Kardex ou mantém o plano de cuidado e documenta no prontuário as intervenções e respostas de cada paciente durante a prestação de assistência. Assim, a enfermagem como profissão, demanda responsabilidade não somente baseada no conhecimento e na habilidade clínica, mas também na administração de uma quantidade enorme de informações relacionadas à assistência prestada ao paciente (CURL et al., 1988).

Sendo a informação é o elemento básico do cuidado, processá-las visando uma assistência com qualidade é uma tarefa difícil, principalmente quando não se adota uma metodologia estruturada. Sabemos que muitas vezes, devido a escassez de pessoal ou a falta de metodologia de assistência adotado pelas instituições de saúde, o enfermeiro em sua prática diária, tem assumido atividades que poderiam ser desenvolvidas por outros profissionais. Assim sendo, têm sido sobrecarregado com atividades burocráticas deixando, por falta de tempo, de registrar no prontuário sobre os pacientes sob sua responsabilidade.

A preocupação crescente com os registros e a conscientização da importância de documentar a assistência de enfermagem prestada ao paciente para assegurar a qualidade e continuidade do trabalho nos diferentes plantões (DIAS, 1998), leva a estimar que os enfermeiros despendem até $50 \%$ de seu tempo coletando, administrando e documentando as

* Enfermeira. Professor Associado do Departamento de Enfermagem Geral e Especializada da Escola de Enfermagem de Ribeirão Preto da Universidade de São Paulo 
informações (PABST et al., 1996; ROSEN \& ROUTON, 1998).

Um dos fatores que contribuem a este acontecimento é o fato do prontuário médico do paciente, considerado a principal fonte de informação na empresa hospitalar, ser baseado em anotações manuais, muitas vezes desorganizadas, inconsistentes, difícil de ler e entender, dificultando aos cuidadores a obtenção das informações que necessitam para incrementar a prática de enfermagem.

Para modificar este cenário podemos por meio da tecnologia da informação instituir os chamados Sistema de Informação em Enfermagem. Estes sistemas usam o computador para processar os dados em informação e apoiar todos os tipos de atividades ou funções de enfermagem (SABA \& McCORMICK, 1986). Visam promover a qualidade da assistência, aprimorando a administração da informação clínica em unidades de internação. Na prática, este sistema de informação, independente ou como componente de um sistema de informação hospitalar, ajuda os enfermeiros no planejamento e documentação do cuidado.

Vários estudos norte-americanos têm demonstrado as vantagens e avanços na aplicação da informática na prática de enfermagem, focalizando os computadores como instrumentos eficazes na organização dos sistemas de informação os quais agilizam o processo de decisão economizando tempo, recursos financeiros, energia, além de aumentar a produtividade e satisfação do trabalhador e aperfeiçoar o cuidado de enfermagem prestado ao paciente. Assim sendo, a implementação de sistemas de informação em enfermagem pode resultar em benefícios, porém a realização de dois terços das vantagens está vinculado ao interesse dos profissionais que atuam diretamente no local, a uma política da Instituição com um grande esforço da administração, além de significante planejamento.

Para se efetuar mudanças e implementar sistemas informatizados é importante estudar as operações do dia-a-dia, ou seja, repensar as regras de realização das atividades diárias. Para tal, recomenda-

\section{REFERÊNCIAS BIBLIOGRÁFICAS}

01. CURL, L.; HOEHN, J.; THEILE, J.R. Computer aplications in nursing. A new course in the curriculum. Comp.Nurs., v. 6, n. 6, p. 263-68, 1988.

02. DIAS, D.C. Análise de evoluções de enfermagem segundo o referencial teórico de Horta e Sistema operacional de Weed. São Paulo, 1998. 152 p. Dissertação (Mestrado) - Escola de Enfermagem da Universidade de São Paulo. se "desenhar" o sistema lógico por meio de Diagrama de Fluxo de Dados (DFD) para compreendermos racionalmente todo o processo de trabalho da enfermagem. É preciso saber quais são as informações que sustentam e descrevem a prática de enfermagem para então instituir estratégias que viabilizem a prestação do cuidado.

Uma pesquisa realizada por ÉVORA (1998) evidencia que o foco principal de investigação da década de 90 referente ao uso do computador na prática de enfermagem, tem sido a informática em enfermagem clínica com tecnologia a beira do leito. As investigações nesta área, conforme OZBOLT \& GRAVES (1993), levam em consideração três dimensões importantes: a) identificação e definição da linguagem de enfermagem e estruturação de seus dados; b) compreensão do julgamento clínico e como o sistema informatizado pode facilitar e não substituir e, c) descobrimento de que sistemas bem desenhados podem transformar a prática de enfermagem.

Introduzir o computador em unidades de internação hospitalar não é um processo simples, principalmente quando se pretende utilizar tecnologia a beira do leito que requer recursos mais avançados. Trata-se de uma tarefa complexa que além de disponibilidade de recursos financeiros demanda tempo e muita responsabilidade dos envolvidos.

Este fato é confirmado por SIMPSON (1995) quando observa que $99 \%$ dos hospitais americanos com mais de 100 leitos são providos de sistemas de informação financeiro, entretanto, apenas 14\% fazem uso de computadores a beira do leito e $9 \%$ têm sistemas de dados clínicos. Embora tenham ocorridos avanços na documentação de enfermagem e no planejamento da assistência, observamos que mesmo em países desenvolvidos, os maiores esforços na informatização acontecem, ainda, em áreas onde o custo pode ser localizado e recuperado com precisão. Documentar quantas pílulas foram ministradas é mais fácil do que delinear o tempo despendido no processo de enfermagem (HUGHES, 1996).

\section{3. ÉVORA, Y.D.M. O paradigma da informática em} enfermagem. Ribeirão Preto, 1998. 139p. Tese (Livre-Docência) - Escola de Enfermagem de Ribeirão Preto da Universidade de São Paulo.

04. HUGHES, L. Choices of nursing systems. In: MILLS, M.E.; ROMANO, C.A.; HELLER, B.R. (eds). Information Management in Health Care. Springhouse, PA: Springhouse Corporation, 1996. p. 92-98. 
Notas e informações...

Rev. latino-am. enfermagem - Ribeirão Preto - v. 7 - n. 5 - p. 127-135 - dezembro 1999

135

05. OZBOLT, J.G.; GRAVES,J.R. Clinical nursing informatics: developing tools for knoledge workers. Nurs.Clin.North Am., v. 28, n. 2, p. 407-25, 1993.

06. PABST, M.K.; SCHERUBEL, J.C.; MINNICK, A.F. The impact of computerized documentation on nurses' use of time. Comp.Nurs., v. 14, n. 1, p. 25-30, Jan/Feb. 1996.
07. ROSEN, E.L.; ROUTON, C.M. American nursing informatics association role survey. Comp.Nurs., v. 16, n. 3, p. 171-5, May/June 1998.

08. SABA, V.K.; McCORMICK, K.A. Essentials of computers for nurses. J.B. Lippincott: Philadelphia, 1986

09. SIMPSON, R. Re-engeneering: embracing technology to improve patient care. Nurs.Manag., v. 26, p. 31-3, 1995. 